\title{
LCC-BASED APPRAISAL OF BALLASTED AND SLAB TRACKS: LIMITS AND POTENTIAL
}

\author{
FILIPPO GIAMMARIA PRATICO ${ }^{1}$, MARINELLA GIUNTA2* \\ ${ }^{1}$ Dept of Information Engineering, of Infrastructures, and Sustainable Energy \\ ${ }^{2}$ Dept of Civil, Energy, Environmental and Material Engineering \\ University Mediterranea of Reggio Calabria, Reggio Calabria, Italy
}

Received 4 January 2018; accepted 21 October 2018

\begin{abstract}
The increase in train speed and axle load is an important goal to achieve in the future. From a technical standpoint, ballastless tracks seem to be suitable to the aim, especially when high-speed passenger trains share the track with freight trains. Based on the above, the primary objective of this study is the comparison between ballasted and slab tracks regarding total costs over the life course. A suitable model to evaluate the total costs of competing solutions is set up. A solution for solving the issue of $\mathrm{CO}_{2}$ price fluctuation and for the quantification of External Costs is also formulated. Life Cycle Costs are estimated based on agency, environmental and present user values. Analyses and results show that when Life Cycle Costing-based approaches are applied: i) Agency Costs have to be considered in the long-term perspective; ii) expected life has an appreciable impact and several solutions and systems, more affordable in the short term, yield unfavourable maintenance and renewal processes; iii) if total costs are considered over track life, the breakeven point is very far from the construction. Furthermore, the differences between the total Present Values of the two solutions become too small to yield sound conclusions in favour of the ballasted vs. the ballastless solution.
\end{abstract}

Keywords: ballasted track (BT), high-speed rail, Life Cycle Costing (LCC), slab track (ST).

\footnotetext{
* Corresponding author. E-mail: marinella.giunta@unirc.it 


\section{Introduction}

According to the SHIFT2RAIL Strategic Master Plan 2015, rising traffic demand, congestion, security of energy supply, and climate change are some of the significant issues, which Europe and the full world are trying to face. Tackling these challenges and issues requires that the railway sector takes on a larger share of transport demand in the next few decades. To this aim, transportation infrastructures are required to be more reliable and resilient, to satisfy the growing mobility necessities efficiently, to reduce environmental impact (carbon footprint), to maintain and upgrade deteriorating infrastructures (renewal processes), and to apply innovative track design and materials. For railway infrastructures, the increase of train speed and axle load calls for a better structural and geometrical stability of the track. The ballastless slab tracks (STs) seem to meet these requirements (Bilow \& Randich, 2000; Gautier, 2015; Pichler \& Fenske, 2013).

Non-ballasted track concept builds on the substitution of sleepers on ballast with concrete slabs on a supporting layer. Concrete slabs contain reinforcement in the neutral axis or at the top and the bottom of the slab. In the first case, reinforcement controls crack width in the concrete when the supporting layer has a substantial bearing stiffness. The second case refers to bending stresses and axial forces, especially in case of soils where some settlements are expected. This system represents the typical solution for bridges and tunnels, due to the rigid support provided by slabs, and for light rail transit (LRT) systems. Various types of ballastless track systems are in service around the world. The most popular ballastless systems are the following: Shinkansen, Rheda, Sonneville-LVT, Züblin, Stedef and Infundo-Edilon. In Italy, a system, similar to Shinkansen, was developed by IPA International Railway System Technology and applied to about $100 \mathrm{~km}$ of high-speed railway. Slab track systems show many advantages compared to traditional ballasted tracks (BT), such as:

1) low maintenance and higher availability;

2) low maintenance cost, approximately 20-30\% less than BT;

3) increased service life (50-60 years);

4) higher lateral stability;

5) reduction of weight and height of the track;

6) more comfortable and more economic vegetation control (Darr \& Fiebig, 2006; Esveld, 2001).

Conversely, weaknesses points are: 
1) higher construction cost;

LCC-Based

Appraisal

of Ballasted

2) higher noise radiation, mainly due to the lack of noise absorption and Slab Tracks: of the ballast bed; possible mitigation measures for noise and vibration further increase the costs of the ST construction (Di Mino, Di Liberto, \& Nigrelli, 2007; Di Mino, Giunta, \& Di Liberto, 2009; Praticò, Vaiana, \& Iuele, 2015; Xin \& Gao, 2010);

3 ) in case of a relevant differential settlement or train derailment, since slabs are quite massive and difficult to repair/substitute, their maintainability (i.e. the probability of performing their successful repair action within a given time) results lower than the one of a BT.

Moreover, when slabs are built on subgrades, special attention must be paid to the interaction concerning bearing capacity, and massive soil improvements are often required (Esveld, 2010). Overall, STs are more expensive to construct, but the lower demand for track maintenance and the higher serviceability during the service life make economically more profitable in a long-term perspective this track system. In the pursuit of comparing the two systems above (ballasted and ballastless), a promising approach is herein proposed and applied regarding an accurate and comprehensive Life-Cycle Costing Analysis (LCCA, based on ISO 15686-5:2008). It encompasses Agency Costs, User Costs, and Externality (AC, UC, and EX, respectively). Life-Cycle Costing provides the theoretical concepts to estimate short-term and long-term costs and performance considering all costs (tangible and intangible) over the time (Esveld, 2001; Praticò \& Giunta, 2018; Stalder, 2001; Zoeteman, 2001). To this end, many data are needed such as construction methods and costs, degradation models (ballast, slab, rail, sleepers), integrated planning of renewal works, grouping of components and track segments, time interval for renewal operations, and budget restrictions (Caetano \& Teixeira, 2015), material and energy consumption through their life cycle (Du \& Karoumi, 2014). Unfortunately, minimal literature and research studies are available to allow the implementation of LCCA for railway tracks. Several studies addressed the lifecycle-related issues for railway transport (Banar \& Özdemir, 2015), railway vehicles (Jun \& Kim, 2007), computer-aided applications (Ciroth, Franze, \& Berlin, 2009), and environmental product declarations (Stripple \& Uppenberg, 2010). Furthermore, a method for addressing synergistically EX and AC is needed. To this end, the fluctuation of environmental costs (e.g. $\mathrm{CO}_{2}$ price per ton) and the uncertainty in the quantification of environmental impacts still make an overall quantification process challenging to set up (Luckow, Stanton, Fields, Biewald, Jackson, 


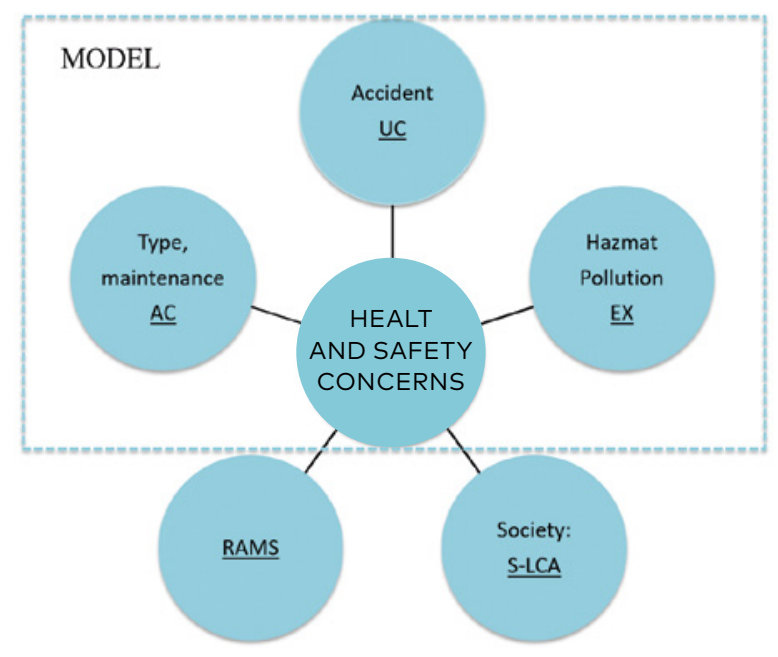

Figure 1. Health and safety issues

\& Fisher, 2015). Another issue is railway safety that is a technical, economic, and social concern. Its relationship with LCC-type analyses is complex, and the risk of underrating or misjudging safety concerns seems quite appreciable (Praticò \& Giunta, 2018). To this end, it is noted that health and safety issues are only partly considered in LCC and Life Cycle Assessment (LCA) analyses. This fact points out that more comprehensive analyses require S-LCA (cf. also ISO 14040:2006 framework; Andrews, 2010) and RAMS approaches (Calle-Cordón, Jiménez-Redondo, Morales-Gámiz, García-Villena, Garmabaki, \& Odelius, 2017; Infralert, 2016; Praticò \& Giunta, 2017, 2018) (Figure 1). Indeed, it is envisaged that only the consideration of society as the primary stakeholder permits achieving the proper consideration of health- and safety-related issues.

Based on the above, the main objectives of the study presented in this paper are:

1) comparing BT and ST systems regarding total costs over life;

2) highlighting potential criticalities in the application of LLC-based methods when environmental and safety issues are considered.

A long-term and synergistic perspective is considered. Life Cycle Costs are estimated based on agency, user, and environmental discounted value and a methodology to overcome uncertainty and fluctuation in environmental costs are proposed. Section 1 deals with the method and explains the innovation of the study. Section 2 focuses on results. Finally, conclusions are drawn. 


\section{Method}

\subsection{Introduction}

In the past, projects were mainly analysed based on investment costs or maintenance costs. Today the principle of Life Cycle Costing Analysis (LCCA) is strongly emerging in the railway sector (Tzanakakis, 2013; Zoeteman, 2006). ISO 15686-5:2008 defines LCC as "the cost of an asset or its parts throughout its life cycle while fulfilling the performance requirements". Life Cycle Costing Analysis is an engineering-economic tool, which compares the relative merits of competing alternatives. Usually, environmental costs are not included in LCCA, whereas other approaches (such as the Whole-Life Costing, WLC, or Life Cycle Assessment, LCA) have a broader scope and include environmental costs. Consequently, from this perspective (which is the one followed in this paper), i.e. when including also environmental costs, minimizing the track system LCC (in terms of Present Worth Value, PWV, or PV, or in terms of Equivalent Uniform Annual Cost, EUAC) results in an increase of the sustainability of the rail superstructure (Giunta, 2016; Giunta \& Praticò, 2017; Praticò \& Giunta, 2016a, 2016b, 2018). The detailed analysis of the costs over the entire life cycle of the track solutions allows assessing the trend of AC (e.g. construction, inspection, maintenance and renewal), UC (e.g. time and accidents), and EX (e.g. mainly related to carbon dioxide equivalent $\left(\mathrm{CO}_{2} \mathrm{e}\right)$ emission of the competing alternatives and recognizing the most convenient. In this section, a model to evaluate the total costs of the competing solutions, traditional rail track and ST, is set up. Tangible and intangible costs, as well as internal (e.g. AC and UC) and EX ( $\mathrm{CO}_{2}$-related) are considered. A solution for solving the issues of $\mathrm{CO}_{2}$ price fluctuation and EX quantification is set up (see Task 4).

\subsection{Procedure}

The main tasks for the application of the method (Figure 2) are the following:

1) Task 1. Design and analysis of alternatives (e.g. BT vs ST);

2) Task 2. Materials and construction-related processes inventory;

3) Task 3. Cost analysis (AC, UC, and EX);

4) Task 4. Balancing (Linear Magnification (LM) in Figure 2);

5) Task 5. Gains. In this task, each option is associated with a given sum of PVs (of the AC, UC, and EX).
LCC-Based

Appraisal

of Ballasted

and Slab Tracks:

Limits

and Potential 


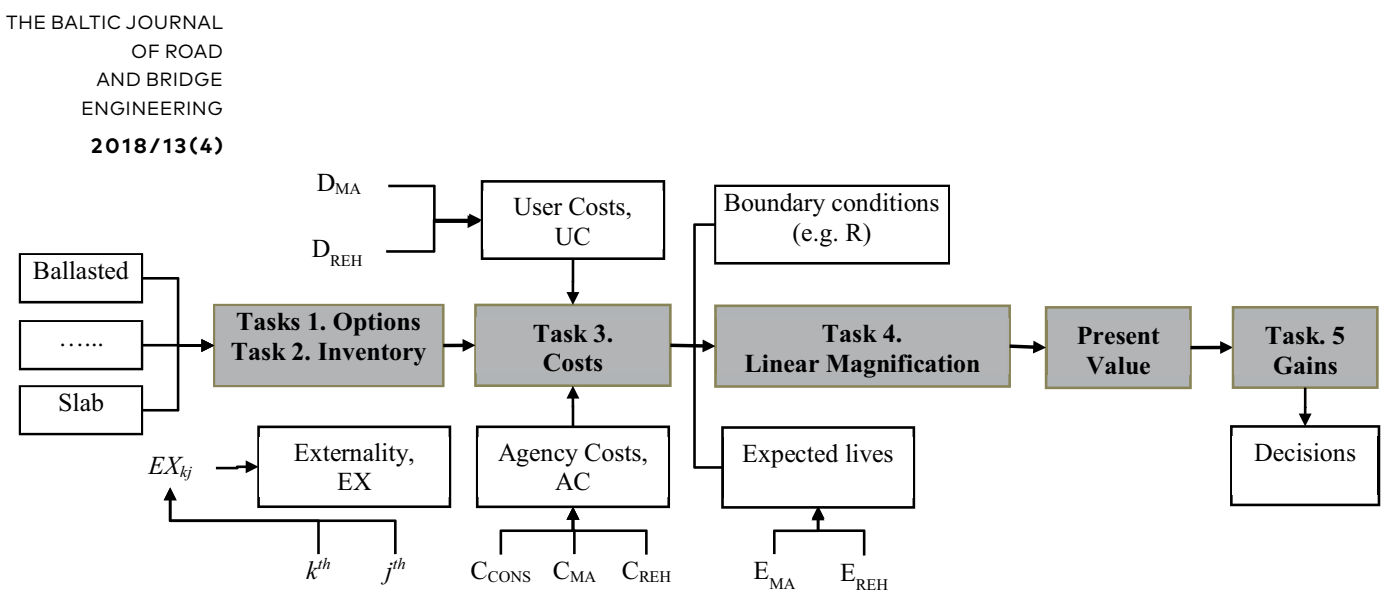

Figure 2. Problem modelling

Note: $D_{M A}$ - delay-related costs for maintenance; $D_{\text {REH }}$ - delay-related costs for rehabilitation; $\mathrm{EX}_{k j}$ - externality generated by the $k^{\text {th }}$ activity/processes and the $j^{\text {th }}$ indicator/impact; $k$ - processes (construction, renewal, maintenance, transportation, quarrying, landfill use, material production (rails, fastenings, baseplates, sleepers/slabs, ballast/elastomer, subballast, concrete, embankment, fixings)); $j$ - indicators $\mathrm{CO}_{2} \mathrm{e}$, sulfur oxide $\left(\mathrm{SO}_{x}\right)$, nitrogen oxides $\left(\mathrm{NO}_{x}\right)$, carbon monoxide $(\mathrm{CO})$, Volatile Organic Compounds (VOC), Particulate Matter (PM), noise, water quality, soil quality, biodiversity, land take, quarries, landfills, and visual effects; $C_{\text {Cons }}$ - construction costs; $C_{R E H}, C_{M A}\left(E_{R E H}\right.$, $E_{M A}$ ) - costs (Expected lives) referred to rehabilitation (REH) or maintenance (MA); R Rate (interest, inflation); LM - Linear Magnification; PV - Present Values; Gains, e.g. $G_{i}=P V_{\text {Ballast }}-P V_{\text {Slab. }}$

\subsection{Procedure}

\subsubsection{Task 1}

Task 1 focuses on the choice of the selected options to compare, i.e. BT and ST.

\subsubsection{Task 2}

Task 2 focuses on Materials and construction-related processes inventory. During this phase, all the components of the BT and ST solutions are considered. Quantities, unit costs, costs, $\mathrm{CO}_{2}$ equivalent per given quantity are assessed based on the analysis of the two options described above. For example, for the BT, rails, sleepers, ballast, subballast, embankment, fastenings, baseplates, and fixings are examined. In Table 1, for each cost component highlighted in Figure 2 (e.g. construction costs), the primary data needed are detailed (e.g. track components, costs, quantities, unit prices, and construction process details). 


\begin{tabular}{|c|c|c|c|c|c|}
\hline Inventory & 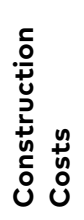 & 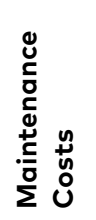 & 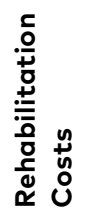 & 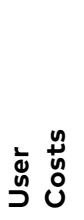 & 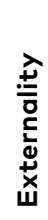 \\
\hline & $\mathrm{C}_{\text {cons }}$ & $\mathrm{C}_{\mathrm{MA}}$ & $C_{\text {REH }}$ & UC & EX \\
\hline Type of track component & $x$ & $x$ & & $x$ & $x$ \\
\hline Quantity & $x$ & $x$ & & $x$ & $x$ \\
\hline Unit Prices & $x$ & $x$ & & $x$ & $x$ \\
\hline Construction processes & $x$ & & & & \\
\hline Traffic in MGT & & $x$ & $x$ & & \\
\hline Speed & & $x$ & $x$ & & \\
\hline The service life of components & & & $x$ & & \\
\hline Scheduling of maintenance & & & & $x$ & \\
\hline Maintenance processes & & $\times$ & & $x$ & $\times$ \\
\hline The service life of track components & & $x$ & $x$ & & \\
\hline Scheduling of renewal & & & $x$ & & \\
\hline Disposal process & & & $x$ & & $\times$ \\
\hline Reconstruction process & & & $x$ & & $\times$ \\
\hline Duration of maintenance activities & & $x$ & & $x$ & \\
\hline Duration of renewal activities & & & $\times$ & $\times$ & \\
\hline Length of delays & & & & $x$ & \\
\hline $\mathrm{CO}_{2} \mathrm{e}$ emissions & & & & & $x$ \\
\hline Price of a ton of $\mathrm{CO}_{2}$ & & & & & $x$ \\
\hline
\end{tabular}

\subsubsection{Task 3}

Task 3 addresses EX, UC and AC. This latter refers to the costs paid by the owner of the track (AC, cf. Figure 2, Table 1, Table 2). They include rehabilitation and maintenance activities. For rehabilitation, each component of the given option (i.e. rails) is supposed to undergo a scheduled process of rehabilitation over time. This tricky task is accomplished based on the international literature, on pieces of information gathered for tracks in service in the country, based on materials (geometry, material quality and quantity), and traffic (Andersson, Björklund, \& Haraldsson, 2016). Assessing the rehabilitation frequency per given component, under given hypotheses of traffic, is a key factor in this task. The main items 
considered are rails, sleepers, and ballast/slab. Table 2 summarises the typical service lives of the components (Calvo, De Oña, LópezMaldonado, Garach, \& De 0ña, 2013; Esveld, 2001; Milford \& Allwood, 2010). In particular, the expected life of rails (e.g. 800 gross million tonnes) depends on a number of parameters. The following are listed: curve or straight track (the inside edge of the top part wears rapidly in low radius curves), rail quality, grade, axle loading and tonnage over the line, rail metallurgy, welded or jointed, maintenance (cyclical grinding), position (outer versus inner) and type of support (slab versus ties).

Rails service life is a vital issue, which interacts with user costs (accidents costs), track type, and rail type. To this end, it is worth noting that:

1) rail cost is about $20 \%$ of the overall superstructure costs for ST and more than 30\% for BT (Popović, Lazarević, Brajović, \& Gladović, 2014);

2) wear, rolling contact fatigue, plastic flow, defects of type 2202 (long-pitch corrugation, inner rail) and 2223 (head checking outer rail) hinder rail ability to withstand loads in safety conditions. Furthermore, jointed tracks or temporary, non-bolted joints affect operations, safety, and track service life (Klockner \& Toft, 2018);

3) continuous and advanced monitoring of defects, rail-grinding strategies (preventive, cyclic and corrective activities) is needed to limit agency and user costs.

For annual maintenance, each option is associated with a given schedule over time regarding maintenance. Typical maintenance activities are rail grinding; replacement of defective rails and sleepers, tamping, track stabilisation, ballast injection. Frequencies, costs, and methods vary, and approaches are different. Bilow \& Randich (2000) and Tsoukantas \& Giannakos (2008) provide the following ballpark figures, for example:

1) non-uniform BT degradation results in a higher rate of rail wear/defects;

2) maintenance of track activities include tamping, adding ballast every 15 MGT (million gross tons per year), surfacing and alignment,

Table 2. The service life of track components

\begin{tabular}{lc}
\hline Component & Service life, years \\
\hline Rail & 28 \\
Ballast + Sleepers & 40 \\
Slab & 60 \\
\hline
\end{tabular}


subgrade improvement, tie replacement (60-100 sleepers per mile per year), and rail replacement (after 3-5 years on heavy haul lines);

3) Annual Maintenance Costs (AMC) of ballastless tracks usually and Slab Tracks: range from $75 \%$ to $90 \%$ than the ones for BT; maintenance and Potential activities result in a short life cycle (1-5 years) and maintenance frequencies are affected by failure patterns and repair methods adopted (mean times to restore services (MTRS) and mean time among failures (MTBF)) (Smith, 2005));

4) marginal railway track renewal costs, calculated as a change in present values of renewal costs from premature renewal following increased traffic volumes, are estimated to approximately 0.002 EUR/GTkm (Andersson, Björklund, \& Haraldsson, 2016);

$5)$ costs of maintenance activities mainly depend on speed and traffic (Baumgartner, 2001; Silavong, Guiraud, \& Brunel, 2014; Thompson, 1986); expenditures for maintenance, occurring at certain times, is distributed annually.

In this study, based on the literature and data gathered, the following Eq. (1) is set up and applied:

$$
\mathrm{AMC}=a\left[2.21 \frac{\mathrm{V}-100}{200}+4.06\right] \cdot \mathrm{GTK}^{\left[-0.05 b \frac{\mathrm{V}-100}{200}+0.63 b\right]},
$$

where AMC - Annual Maintenance Costs in kEUR, thousands of Euros/single track/kilometre; $V$ - maximum speed allowed in the track, km/h; GTK - refers to gross ton-kilometres, ton·km; $a$ and $b$ coefficients to calibrate.

The rationale behind Eq. (1) is very simple:

1) for a given speed, the higher the GTK, the higher the AMC;

2) for a given GTK, the higher the speed, the higher the AMC;

3) higher speeds correspond to higher AMC and higher first derivatives.

For $a=b=1$, the underlying data of Eq. (1) are the ones in Baumgartner (2001). Eq. (1) allows deriving AMC for a broader spectrum of speeds and GTKs. It seems important to highlight that AMC is influenced by many other supplementary variables, such as system typology and frequency of monitoring.

Each maintenance operation corresponds to a given cost and a corresponding PV. Present Values are assessed based on the hypotheses hereafter described regarding inflation and interest rate. For the options considered, in pursuit of the estimation of AC for the given alternative, it is essential to observe that the initial construction cost is different, as well as the construction period and the costs incurred in successive rehabilitation works, and the so-called Salvage Value (Residual Value).

Based on the above, the following algorithm for the PV is set up: 


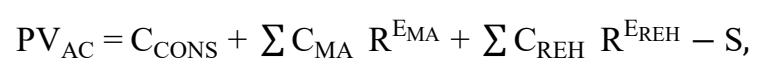

where $\mathrm{PV}_{\mathrm{AC}}$ - the Present Value of Agency Costs; $\mathrm{C}_{\text {cons }}$ - the Construction Cost; $\mathrm{C}_{\mathrm{MA}}$ - the Maintenance Cost; $\mathrm{C}_{\mathrm{REH}}$ - the Rehabilitation Cost; $\mathrm{E}_{\mathrm{REH}}$ - the expected time for rehabilitation; $\mathrm{E}_{\mathrm{MA}}$ - the expected time for maintenance; $\mathrm{S}$ - the salvage value; $\mathrm{R}$ - rate, where $i$ - the inflation rate and $r$ - the interest rate.

Importantly:

1) the expression used above for $R$ allows considering both the nominal interest rate $(r)$ and the inflation rate $(i)$;

2) the real interest rate $\left(r_{r}\right)$ is expressed as a function of $r$ and $i$ through the relationship $\mathrm{R}=\frac{1+i}{1+r}=\left(1+r_{r}\right)^{-1}$;

3) the expression above permits complying with real discount rates $\left(r_{r}\right)$ which reflects the real-time value of money with no inflation premium;

4) for the case under study, a real interest rate of about $3.8 \%$ (average value in 2012-2014 by Trading Economics) was used and corresponds to $\mathrm{R}=0.963$ with $r=0.08$ and $i=0.04$ (Table 4);

5) based on the above, in the following, analyses are focused on the remaining aspects.

As already, mentioned, maintenance scheduling varies, and their cost is modelled as annual (AMC). When the period of analysis approaches infinity, the salvage value approaches zero, and the following Eq. (3) applies:

$$
\mathrm{PV}_{\mathrm{AC}}=\mathrm{C}_{\text {CONS }}+\mathrm{C}_{\mathrm{MA}} \mathrm{R}^{\mathrm{E}_{\mathrm{MA}}}\left(1-\mathrm{R}^{\mathrm{D}}\right)^{-1}+\mathrm{C}_{\mathrm{REH}} \mathrm{R}^{\mathrm{E}_{\mathrm{REH}}}\left(1-\mathrm{R}^{\mathrm{D}}\right)^{-1},
$$

where $D$ - the expected life of the as-design track.

Task 3 also focuses on UC. They include delays $\left(P V_{D}\right)$, vehicleoperating costs $\left(\mathrm{PV}_{\mathrm{voc}}\right)$, and accident costs $\left(\mathrm{PV}_{\mathrm{A}}\right)$ (fatal, nonfatal, property damages). According to Esveld (2001), the most critical feature of a decision support system, dealing with maintenance strategy, is the relationship between track use and maintenance. This fact explains the importance of UC for railways tracks. Furthermore, the same author observes that the infrastructure use determines largely:

1) the maintenance needs, i.e. as a function of traffic volume and type;

2) the impact of track failures, i.e. cumulative train delays and cancellations;

3) the slots available for maintenance.

Consequently, the estimate of user costs is a very complex task.

Importantly, when the LCC breakdown is considered, increasing costs of traffic disruption is estimated to be about the tenth part of $\mathrm{C}_{\mathrm{MA}}$ and $\mathrm{C}_{\mathrm{REH}}$. 
User Costs, as mentioned, include $\mathrm{PV}_{\mathrm{D}}$, originated by work zones of given length and duration (Walls \& Smith, 1998). Lovett, Dick, \& Barkan (2015a), identifies two categories of delays: routine, experienced during normal operations, including crew changes, meets, passes, and local speed restrictions, and irregular, including maintenance/renewal, accidents, and short-term speed restrictions based on track conditions. This paper takes into account delays originated by maintenance and renewal activities. This category of delays depends on track type, uncertainties relate to the expected operating conditions and maintenance needs of innovative technologies (Zoeteman, 2001).

The cost of train delay per hour varies based on a variety of factors broken into five main categories: crew, cars, locomotives, and fuel and most of these costs vary with train composition (Lovett, Dick, Ruppert, \& Barkan, 2015b). By literature (Dingler, Lai, \& Barkan, 2011; Lai \& Barkan, 2009; Lovett, Dick, \& Barkan, 2015a; RSAC, 1999; Schafer \& Barkan, 2008; Schlake, Barkan, \& Edwards, 2011). Delay costs for railroads range from 200 EUR to more than 900 EUR per train-hour. Assuming an average train composition, then crew, car, lading, and locomotive, costs are approximately 900 EUR train-hour. Based on the above the following Eq. (4) applies:

$$
\mathrm{PV}_{\mathrm{UC}}=\mathrm{PV}_{\mathrm{D}}+\mathrm{PV}_{\mathrm{A}}+\mathrm{PV}_{\mathrm{VOC}}=\sum \mathrm{C}_{\mathrm{D}_{\mathrm{REH}}} \mathrm{R}^{\mathrm{E}_{\mathrm{REH}}}+\sum \mathrm{C}_{\mathrm{D}_{\mathrm{MA}}} \mathrm{R}^{\mathrm{E}_{\mathrm{MA}}}+\mathrm{PV}_{\mathrm{A}}+\mathrm{PV}_{\mathrm{VOC}} \text {, }
$$

where $P V_{U C}$ - the Present Value of User Costs, $P V_{D}, P_{A}, P V_{V O C}$ are the Present Values of the cost due to delays (D), accidents (A), and vehicle operating costs (VOC), respectively; $\mathrm{C}_{\mathrm{D}_{\mathrm{REH}}}$ - the cost of delays due to the rehabilitation; $C_{D_{M A}}$ - the cost of delays due to the maintenance; $E_{R E H}$ and $\mathrm{E}_{\mathrm{MA}}$ - the expected time for rehabilitation and maintenance, respectively.

By referring to accident costs, the fatalities per billion passengermiles are around 0.4 for trains, 7.0 for cars, and 0.1 for aeroplanes.

Externalities (Task 3) include transportation, quarrying, landfill use, material production (cement, steel, rubber) and impact construction/renewal/maintenance activities which imply environmental concerns such as climate change $\left(\mathrm{CO}_{2} \mathrm{e}\right)$, air quality $\left(\mathrm{SO}_{\mathrm{x}}\right.$ $\mathrm{NO}_{\mathrm{x}}, \mathrm{CO}, \mathrm{PM}$ ), noise, water quality, soil quality, biodiversity, land take, quarries, landfills, and visual effects.

Milford \& Allwood (2010) investigated the $\mathrm{CO}_{2}$ impact of current and future rail track systems. They observed that vehicle operations contribute for approximately $70 \%$ of lifecycle $\mathrm{CO}_{2}$ emissions, construction, maintenance and disposal of infrastructure for nearly $20 \%$, and vehicle manufacturing, maintenance and disposal for the remaining $10 \%$. Further, they found that the current track configurations with concrete sleepers have the lowest $\mathrm{CO}_{2}$ impact, followed by steel, hardwood and softwood, while several potential
Appraisal

of Ballasted and Slab Tracks:

Limits

and Potential 
future rail track designs potentially lead to up to a $40 \%$ reduction in $\mathrm{CO}_{2}$ impact.

Åkerman (2011) estimated that the proposed high-speed rail track in Sweden is expected in lifecycle emissions reductions for about 550,000 tons of $\mathrm{CO}_{2}$-equivalents per annum by $2025 / 2030$, with almost $60 \%$ through a shift from truck to rail freight and $40 \%$ based on a shift from air and road travel to high-speed rail travel.

Westin \& Kågeson (2012) analysed the climate implications of investments in high-speed railway lines and found that traffic volumes of more than 10 million annual one-way trips are usually required to balance the annualised emissions from the railway construction.

For production-related issues (aggregate, cement, steel), carbon dioxide is one of several heat-trapping greenhouse gases (GHGs) emitted. Based on the European Commission Report of 2010, these gas emissions are the primary cause of global warming. To this end, a carbon dioxide equivalency is usually used (amount of $\mathrm{CO}_{2}$, which has the same global warming potential (GWP), when measured over a specified timescale, generally, 100 years). It is usually expressed in grammes of carbon dioxide equivalents per $\mathrm{km}$ (god $/ \mathrm{km})$. For example, the $\mathrm{CO}_{2} \mathrm{e}$ figure of cementations material is about $950 \mathrm{~kg} \mathrm{CO}_{2}$ per tonne (Lee, Lee, \& $\mathrm{Kim}, 2008$ ), while the $\mathrm{CO}_{2} \mathrm{e}$ figure of asphalt concrete is about $60 \mathrm{~kg}$ $\mathrm{CO}_{2}$ per tonne (Zwan, 2012). The quantification of EX is carried out by considering:

1) the quantity of $\mathrm{CO}_{2}$ equivalent corresponding to the given process and material;

2) the price of a ton of $\mathrm{CO}_{2}$ expressed regarding Social Cost of Carbon;

3) the remaining factors associated to the process under consideration (quarrying, landfill, transportation-related emissions);

4) the algorithm set up in Eqs (5)-(7). Based on this discussion, different classes of externalities, $\mathrm{EX}_{k j}$ are considered, where $j$ refers to the $j^{\text {th }}$ impact (e.g. $\mathrm{CO}_{2}$ equivalent, air quality, noise, biodiversity), while $k$ stands for the $k^{\text {th }}$ activity (e.g. $k=0$ construction, $\mathrm{EX}_{0}, k^{\text {th }}$ successive rehabilitation/routine maintenance, $\mathrm{EX}_{k}$ ):

$$
\mathrm{EX}_{\mathrm{kj}}=\sum_{\mathrm{j}} \mathrm{Q}_{\mathrm{kj}} \mathrm{UP}_{\mathrm{kj}},
$$

where $\operatorname{EX}_{k j}-$ the class of Externality, $j-$ a $j^{\text {th }}$ impact, e.g. $\mathrm{CO}_{2}$ equivalent; $k$ - the $k^{\text {th }}$ activity, e.g. construction, $\mathrm{EX}_{0}$, successive $k^{\text {th }}$ rehabilitation/routine maintenance, $\mathrm{EX}_{k} ; \mathrm{Q}_{k j}$ - the quantity; $\mathrm{UP}_{k j}$ - the unit price of the Externality.

For the estimation of $\mathrm{CO}_{2}$ emissions (transport related), the following Eq. (6) is used: 


$$
\mathrm{EX}_{k \mathrm{CO}_{2}}=\sum_{j} \frac{\mathrm{VN}_{k j}}{\mathrm{CA}_{k j}} \mathrm{D}_{k j} \mathrm{EM}_{k j} \mathrm{FC}_{k j},
$$

where - $\mathrm{EX}_{k \mathrm{CO}_{2}}$ the cost of the $\mathrm{CO}_{2}$ emissions, $k$ refers to the $k^{\text {th }}$ rehabilitation process; $\mathrm{VN}_{k j}$ - the volume of material needed, $\mathrm{m}^{3} ; \mathrm{CA}_{k j}-$ the average truck capacity, $\mathrm{m}^{3}, \mathrm{D}_{k j}$ - the average distance to cover (round trip), $\mathrm{km} ; \mathrm{EM}_{k j}$ - an emission surcharge factor (EUR/l), $\mathrm{FC}_{k j}$ - stands for fuel consumption $(\mathrm{l} / \mathrm{km}), j$ - refers to a given process-material.

Finally, it results:

$$
\mathrm{PV}_{\mathrm{EX}}=\mathrm{EX}_{0}+\sum_{k} \mathrm{EX}_{k} \mathrm{R}^{\mathrm{E}_{k}}\left(1-\mathrm{R}^{\mathrm{D}}\right)^{-1},
$$

where $\mathrm{PV}_{E X}$ - the Present Value of Externality; $\mathrm{EX}_{0}$ - the Externality due to the construction stage, $\mathrm{EX}_{k}-$ the Externality due to the $k^{\text {th }}$ activity, $\mathrm{E}_{k}$ - the expected time of the $k^{\text {th }}$ activity (maintenance or rehabilitation).

\subsubsection{Task 4}

Task 4 deals with the derivation of a sound quantification of the $\mathrm{EX}$, despite the evidence of the fluctuation of the $\mathrm{CO}_{2}$ price per ton. The quantification of the $\mathrm{CO}_{2}$ emissions is a well-established practice (European Union Emissions Trading System (EU ETS) (Sijm, Neuhoff, \& Chen, 2006), but the fluctuation of the carbon price is a matter of fact (Chevallier, 2012). This fact implies inconsistent decision-making processes because of a biased evaluation of alternatives against objectives (Tasks 3 and 5 in Figure 2). To this end, an indicator ( $v$ ), that refers to the most critical relationship between internal and internalised costs, is derived in Eq. (8).

$$
v=\min _{i=1,2, k} \frac{\mathrm{PV}_{\mathrm{AC}_{i}}+\mathrm{PV}_{\mathrm{UC}_{i}}}{\mathrm{PV}_{\mathrm{EX}}}
$$

This indicator, applied to each solution, leads a Linear Magnification/Reduction of EX. In other terms, through the introduction of the abovementioned coefficient $v$, the relationship between the three main classes of costs, i.e. AC, UC, and EX, is balanced.

The following procedure is herein proposed in the case of $\mathrm{PV}_{\mathrm{Ex}_{i}}<\mathrm{PV}_{\mathrm{AC}_{i}}+\mathrm{PV}_{\mathrm{UC}_{i}}$, for each i-th design alternative:

$$
\mathrm{PV}_{\mathrm{EX}_{i}}^{\prime}=v \mathrm{PV}_{\mathrm{EX}_{i}}
$$

Consequently, in just one case, named $j$, the following two Eqs (10)-(11) result:

$$
\begin{gathered}
\mathrm{PV}_{\mathrm{AC}_{\mathrm{j}}}+\mathrm{PV}_{\mathrm{UC}_{\mathrm{j}}}=v \mathrm{PV}_{\mathrm{EX}_{\mathrm{j}}}=\mathrm{PV}_{\mathrm{EX}_{j}^{\prime}}^{\prime} \\
\mathrm{PV}_{j}=\mathrm{PV}_{\mathrm{AC}_{j}}+\mathrm{PV}_{\mathrm{UC}_{j}}+\mathrm{PV}_{\mathrm{EX}_{j}}^{\prime}=2 \mathrm{PV}_{\mathrm{EX}_{j}^{\prime}}^{\prime} .
\end{gathered}
$$

In pursuit of the estimation of the overall gain for each solution, it is worth noting that AC, UC and EX contribute to the overall PV as per Eq. (12):

$$
\mathrm{PV}=\mathrm{PV}_{\mathrm{AC}}+\mathrm{PV}_{\mathrm{UC}}+\mathrm{PV}_{\mathrm{EX}}^{\prime} \text {. }
$$

LCC-Based

Appraisal

of Ballasted

and Slab Tracks:

Limits

and Potential 


\subsubsection{Task 5}

In Task 5, gains (G) are derived, as per Eq. (13). Based on the abovementioned three different classes (AC, UC, and EX'), it is possible to estimate the gain originated by one solution (for example, ST) with respect to the control case (BT) with consideration of only $A C\left(G_{A C}\right)$ or only $\operatorname{EX}\left(\mathrm{G}_{\mathrm{EX}}\right)$, or any other combinations as appropriate:

$$
\begin{gathered}
\mathrm{G}=\left(\mathrm{PV}_{\mathrm{AC}}+\mathrm{PV}_{\mathrm{UC}}+\mathrm{PV}_{\mathrm{EX}}\right)_{\text {ballast }}-\left(\mathrm{PV}_{\mathrm{AC}}+\right. \\
\left.\mathrm{PV}_{\mathrm{UC}}+\mathrm{PV}_{\mathrm{EX}}\right)_{\text {slab }}=\left[\left(\mathrm{PV}_{\mathrm{AC}}\right)_{\text {ballast }}-\left(\mathrm{PV}_{\mathrm{AC}}\right)_{\text {slab }}\right]+\left[\left(\mathrm{PV}_{\mathrm{UC}}\right)_{\text {ballast }}-\right. \\
\left.\left(\mathrm{PV}_{\mathrm{UC}}\right)_{\text {slab }}\right]+\left[\left(\mathrm{PV}_{\mathrm{EX}^{\prime}}\right)_{\text {ballast }}-\left(\mathrm{PV}_{\mathrm{EX}}\right)_{\text {slab }}\right]=\mathrm{G}_{\mathrm{AC}}+\mathrm{G}_{\mathrm{UC}}+\mathrm{G}_{\mathrm{EX}^{\prime}} .
\end{gathered}
$$

Positive gains correspond to solutions better than the traditional one, i.e. BT.

\section{Results}

Two design alternatives, BT and ST, were considered (Tables 3 and 4). The method application was referred to a theoretical (hypothetical) stretch of $1000 \mathrm{~m}$ double-track, high-speed railroad. For the traditional BT, the primary engineering inputs are detailed in Table 3.

The ST system considered in this paper is the Japanese Shinkansen. It consists of reinforced pre-stressed concrete slabs measuring $4.93 \times 2.34 \times 0.19 \mathrm{~m}$ and weighing approximately 5 tonnes (Esveld, 2001) located over a sublayer stabilised with cement (concrete roadbed). Cylindrical bollards prevent lateral and longitudinal movement of the slabs. For the two alternatives, construction cost includes the costs of the following components: rails, sleepers/concrete slabs, fastenings, baseplate, ballast/elastomeric pad, subballast/concrete base, embankment. The quantification of these costs was carried out based on Italian railway projects and was consistent with the international literature (Table 4). For the EX, for each component, the total amount of greenhouse gases produced to, directly and indirectly,

Table 3. Ballasted track components

\begin{tabular}{ll}
\hline \multicolumn{1}{c}{ Components } & \multicolumn{1}{c}{ Type } \\
\hline Rail & $60 \mathrm{E} 1$ (UIC 60), $60 \mathrm{~kg} / \mathrm{ml}$, continuous welded \\
Sleepers & pre-stressed mono-block type RFI 260V- AV \\
Fastenings & elastic fastening type Vossloh W14 AV \\
Ballast & crushed stones, $500 \mathrm{~mm}$ (average depth) \\
Subballast & cement-treated layer, $200 \mathrm{~mm}$ deep \\
\hline
\end{tabular}




\begin{tabular}{ll}
\hline \multicolumn{1}{c}{ Components } & Default Cost $^{*}$ (10 ${ }^{3}$ EUR) \\
\hline Rails (ballasted/slab track) & $240-300$ \\
Sleepers & 115 \\
Slabs & 165 \\
Ballast & 226 \\
Elastomer & 369 \\
Subballast & 105 \\
Concrete layer & 53 \\
Embankment (underneath ballasted/slab track) & $120-200$ \\
Fastenings, Baseplates, Fixings & 162 \\
Annual maintenance costs of ballasted/slab track & $30 / 8$ \\
Renewal costs of ballasted/slab track & $818 / 1018$ \\
Traffic, MGT/year/km & 6 \\
Speed, km/h & 200 \\
Interest rate ( $r$ ) & 0.04 \\
Inflation rate (i) & 0.08 \\
The carbon price, EUR/ton & 11 \\
\hline
\end{tabular}

Note: * costs are referred to $1 \mathrm{~km}$ of double track

support railway-related activities (equivalent tons of carbon dioxide) was estimated (Leung, 2009; Milford \& Allwood, 2010). The carbon price assumed refers to the Social Carbon Cost, such as the cost of an additional ton of $\mathrm{CO}_{2}$ emissions (van den Bergh \& Botzen, 2015). Figures 3-7 summarise results.

Figure 3 focuses on two main pieces of information regarding the sustainability of a track system: construction costs and carbon footprint. $X$-axis refers to the construction cost of a given item, e.g. rails, as a percentage of the total construction cost. $Y$-axis reports the carbon footprint $\left(\mathrm{CO}_{2} \mathrm{e}\right)$ of the same item as a percentage of the total $\mathrm{CO}_{2} \mathrm{e}$. Ballasted track and ST are the options under analysis. Both $x$ and $y$ variables are independent of prices fluctuations (assumed that the costs of the different items are linearly dependent) and from $\mathrm{CO}_{2} \mathrm{e}$-associated cost. Three main importance levels are highlighted. The first level includes rails, elastomers, slabs, and sleepers. Rails are a common component whose construction cost is about $25 \%$ and $\mathrm{CO}_{2 \mathrm{e}}$ about $30 \%$, while elastomers are mainly used in the ST, with a construction cost of about $30 \%$ and $\mathrm{a} \mathrm{CO}_{2} \mathrm{e}$ about $25 \%$. As for slabs, 


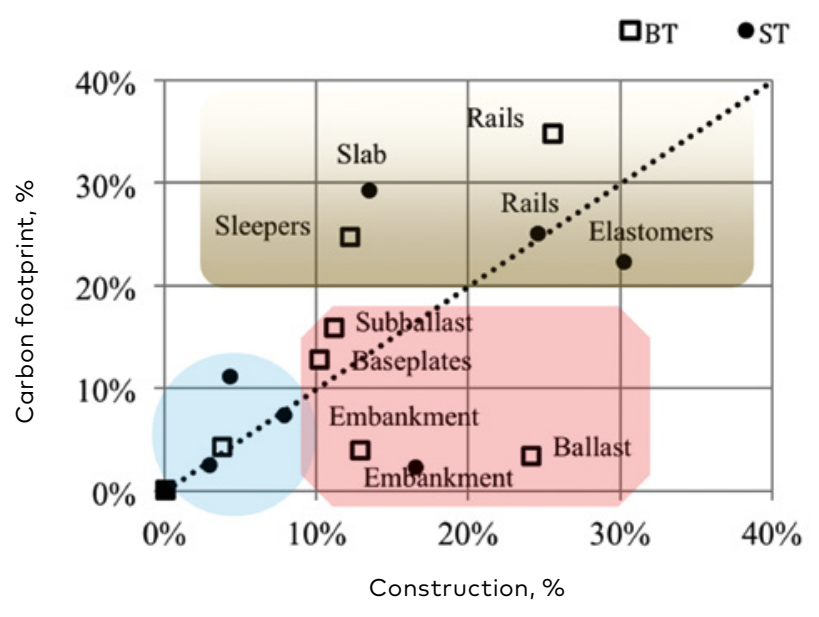

Figure 3. Construction versus carbon footprint

sleepers, being a cement concrete-based product, have a quite low cost (about $10-15 \%$ ) and a quite high $\mathrm{CO}_{2} \mathrm{e}$ (about 25-30\%). The second class includes ballast, subballast, baseplates, and embankment. Construction costs range from $10 \%$ to $25 \%$, while $\mathrm{CO}_{2} \mathrm{e}$ is lower than about $25 \%$. The remaining items, such as fastenings, baseplates, and fixings, have construction costs and $\mathrm{CO}_{2} \mathrm{e}$ lower than about $10 \%$. Materials having high mechanical performance and quite complex production process usually yield a correspondent construction cost and $\mathrm{CO}_{2} \mathrm{e}$ very high. In contrast, materials such as soil and ballast or subballast (hot mix asphalt or cement treated course) (Oh, 2014; Praticò, Vaiana, \& Giunta, 2013; Praticò, Vaiana, Giunta, Iuele, \& Moro, 2013), although associated to significant construction volumes, yield quite low percentages regarding both construction cost and $\mathrm{CO}_{2} \mathrm{e}$.

Figure 4a shows how the PV of the two options varies over time (AC). The assumptions were the following:

1) the costs of rehabilitation were considered equal to the construction costs for the given component, and this implies that the rehabilitation cost of STs is higher than the one of BTs;

2) the renewal activities are more time-consuming for STs.

The construction cost of the ST is higher than the one of the BT (1.2 million EUR vs 0.9 million EUR), but after just twenty years the slab solution exhibits a PV increasingly lower than the one yielded by the BT. This fact implies that starting from 20 years after construction, ST is better than BT (AC perspective). After about one century, the BT yields an overall (internal) PV 1.2 times higher than the one associated to the ST. Note that BEP stands for a breakeven point. 

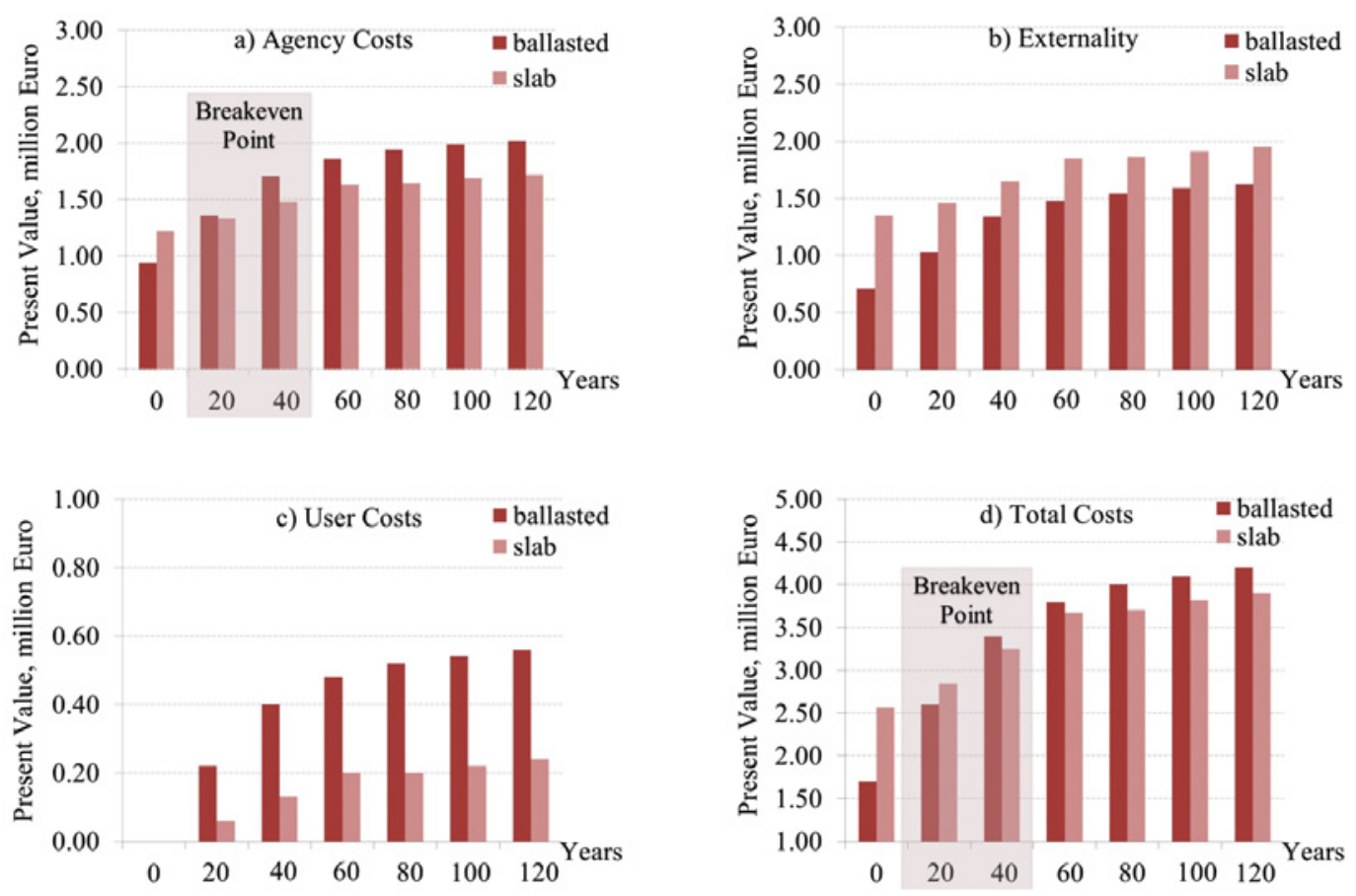

Figure 4. Costs over the time

Figure $4 \mathrm{~b}$ displays the PV of the UC over time. The fundamental element that underlies the results is that the maintenance process is slightly more expensive (regarding frequencies and durations) for the BT. Importantly, because of accidents, more data are needed for a comprehensive analysis. The magnitude of the PV for both of the solutions above appears consistent with the literature (Esveld, 2001; Pichler \& Fenske, 2013; Schilder \& Diederich, 2007). Apart from this observation, BT yields a cost 2.3 times higher than the one exhibited by the ST after the same period of analysis (more than one century).

Figure 4c illustrates the PV of the EX overtime for the options above. The as-built $\mathrm{BT}$ yields an EX (related to $\mathrm{CO}_{2}$ costs) lower than the one associated to the ST, by a factor 0.8. Surprisingly, this tendency undergoes only slight modifications over time, being the ballasted solution still the optimal solution after more than one century.

Figure $4 \mathrm{~d}$ illustrates the sum of the PV ( $y$-axis) over time ( $x$-axis). The breakeven point (above detected for about 20 years) now moves towards 40 years, due to the impact of $\mathrm{CO}_{2} \mathrm{e}$-related costs. After more than one century, the overall PV of the BT appears comparable to the one of the ST. The corresponding ratio accounts for an increase of just 


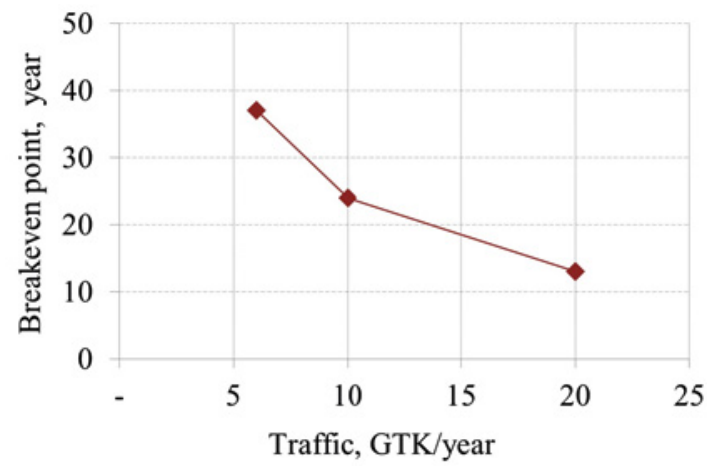

Figure 5. Breakeven point of total costs vs traffic

8\%. Such a condition calls for a more in-depth investigation. In more detail, it appears noteworthy to underline that the same uncertainty, which is intrinsic to the estimate of PV (due to the variance associated with materials, processes, and environmental factors), allows justifying a certain caution in expressing a clear "dominance" of one solution on the other one. However, the results are consistent with the literature. Austrian studies (Mach, 2011) report a breakeven point for the total track costs after 24 years of operation, based on a daily track loading of about 70000 gross-tons.

Finally, Figure 5 illustrates how the breakeven point (BEP, years, $y$-axis) of total costs varies as a function of traffic (gross ton kilometre, GTK, per year, $x$-axis). This sensitivity analysis points out that, under the given hypotheses, the higher the traffic is, the lower the BEP becomes, the more convenient the slab solution becomes.

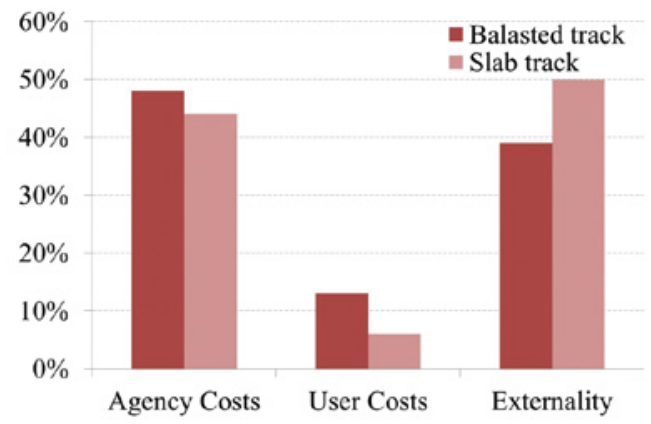

a) 120 years

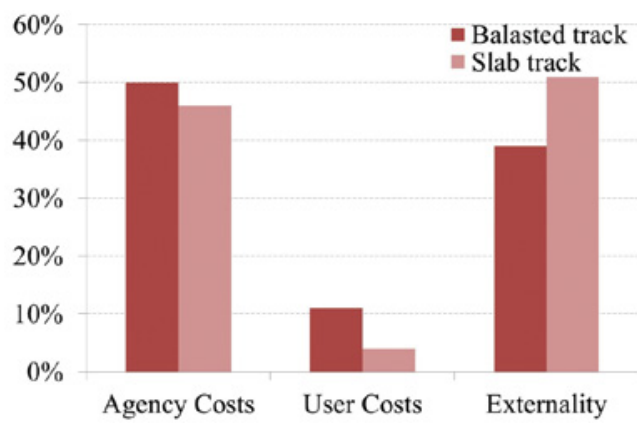

b) 30 years

Figure 6. Classes of costs for the two options 


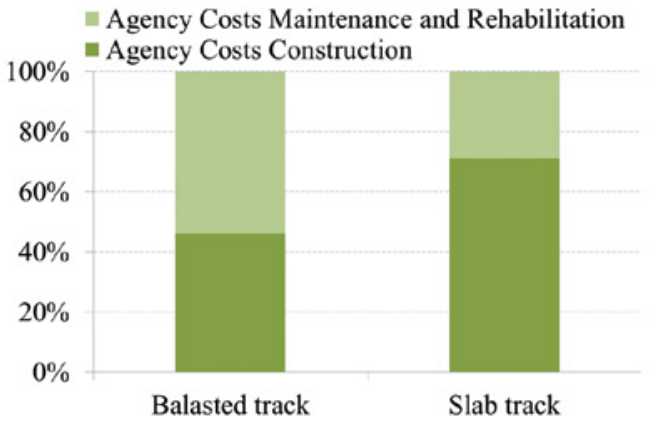

a) 120 years

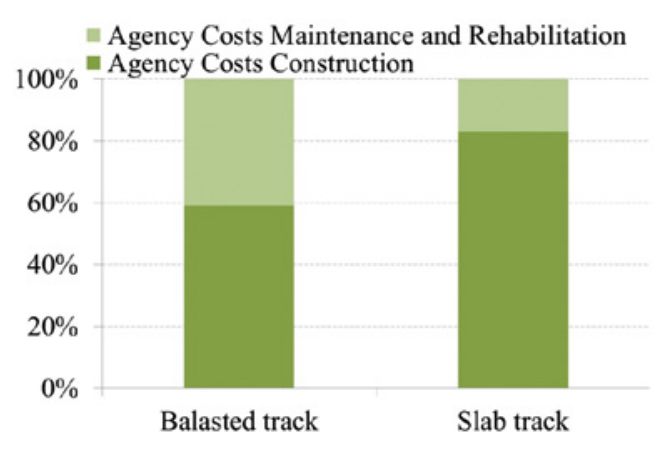

b) 30 years

Figure 7. Construction versus Maintenance and Rehabilitation Costs for ballasted track and slab track

Figure 6 focuses again on time dependency. In Figure $6 \mathrm{a}$ the three classes of costs are compared, i.e. AC, UC, and EX'. Note that the apex (EX') refers to the fact that costs were "balanced" to avoid inferences biased by $\mathrm{CO}_{2}$ cost fluctuation. The period considered is 120 years (approximately twice the expected life of PCC slabs), while the abovementioned two options are considered (BT and ST). Figure 6a shows that ACs and UCs are higher when the BT is considered.

In contrast, the slab solution yields higher EX'. This result is crucial because it proposes again the familiar conundrum that often divides high-tech innovation from traditional solutions. The same applies to Figure $6 \mathrm{~b}$, where the period of analysis is lower than the one considered above. Figure 7a refers to agency costs and illustrates the comparison between construction (Constr) and Maintenance and Rehabilitation Costs (M\&R), for the two solutions. Each solution (BT or ST) is scaled to $100 \%$. The BT yields a lower initial cost (construction), while over time higher costs on maintenance and rehabilitation are needed. This occurrence plays an outstanding role in decision-making because of the available budget and because of the political process, which usually hinders from considering other choices. When the abovementioned evaluation, carried out after 120 years, is compared to a short-term analysis (Figure $7 \mathrm{~b}$ ), the percentage of cost referred to construction appears increased. This notwithstanding BT still yields a percentage distribution, which emphasises easier access to funding.

Finally, it is worth noting that further development of this study will emerge when LCC approaches are merged with RAMS and S-LCA approaches. Indeed, combined RAMS, LCC, and S-LCA methodologies for 
railway and road transport infrastructures allow providing relevant and more comprehensive insights regarding investment and maintenance planning.

\section{Discussion of results}

Tangible and intangible costs govern the suitability of a track to fit transportation and environmental demand. Merging the technical issues and environmental concerns is a challenging task, and to this aim, a model has been formalised, based on the analysis of the cost of the cycle of life of BT and ST. The model allows considering environmental concerns as well as technical requirements and entails their balance through a specific and innovative algorithm. Care must be taken in deriving the external costs for a given scenario because reasonable assumptions are needed, especially when relevant laboratory and field data are unavailable for this purpose. The innovation of the paper pertains to the following main points. In this study, environmental impact and other costs are treated together: the well-known conundrum of dealing at the same time with environmental costs and remaining costs is herein solved through Eqs (8) and (9). This synergistic approach is innovative because the existing literature does not provide sound solutions to the issue of the fluctuation of EX. Consequently, the objectivity of comparisons is hindered from achieving a sound result because studies refer to a given historical period. The study described in this paper overcomes this drawback through the normalisation as per Eqs (8) and (9). Another issue of the existing literature refers to the consideration of just one life cycle. This fact implies that the relevance of financial flows is neglected or underrated. On the contrary, in this study real interest rates are considered for an infinite number of cycles. Eq. (3) illustrates this concept. The form of Eq. (3) contains the denominator $\left(1-\mathrm{R}^{\mathrm{D}}\right)$, which derives from the limit of a running sum.

\section{Conclusions}

Authors are aware that conducting such a comprehensive analysis requires big data sets. Anyhow, data gathered, and analyses carried out lead to the following conclusions.

1. Agency Costs cannot be analysed based on the sole construction costs in a short period. Indeed, although the magnitude of construction cost is very high (compared to the remaining costs), expected life has an appreciable impact. Consequently, solutions and systems 
more affordable in the short-term yield maintenance, and renewal processes unfavourable: the best initial solution is the worst for longterm goals.

of Ballasted and Slab Tracks:

2. Maintenance and renewal processes affect both long-term agency and Potential costs and user costs, due to delays. High-frequency tracks and highspeed tracks result greatly influenced. This component cost depends on transport demand, and it turns out that these hypotheses affect results. Furthermore, railway traffic may change over time, due to new industrial settings, but it is important to observe that delays have exceptional importance regarding public opinion and this element makes the difference in referring to rail freight corridors or in contrast to high-speed tracks.

3. Ballasted tracks present environmental impacts lower than the one of the slab track system considered. Cement-related carbon footprint hinders the diffusion of slab track systems for minor applications.

4. From a more comprehensive standpoint, when tangible and intangible costs are considered over track life, the breakeven point (between ballasted track and slab track) is "far" from construction, i.e. many years pass after the construction, depending on the level of traffic.

5. Overall, the "distance" between the total Present Values of the two solutions under analysis becomes too small to yield sound conclusions in favour of the ballasted vs the ballastless solution. This fact implies that the type of track (rail freight corridor, high-speed track, local tracks) causes a change regarding both algorithm output and decision-making.

6. Social concerns about safety and maintainability demand proper attention in the analyses above. This point calls for further research into the Social Life Cycle Assessment and Reliability, Maintainability, Availability and Safety analyses.

\section{REFERENCES}

Åkerman, J. (2011). The role of high-speed rail in mitigating climate change-The Swedish case Europabanan from a life cycle perspective. Transportation Research Part D: Transport and Environment, 16(3), 208-217. https://doi.org/10.1016/j.trd.2010.12.004

Andersson, M., Björklund, G., \& Haraldsson, M. (2016). Marginal railway track renewal costs: A survival data approach. Transportation Research Part A: Policy and Practice, 87, 68-77. https://doi.org/10.1016/j.tra.2016.02.009

Andrews, E. S. (2010). Guidelines for social life cycle assessment of products. UNEP/Earthprint. 
Banar, M., \& Özdemir, A. (2015). An evaluation of railway passenger transport in Turkey using life cycle assessment and life cycle cost methods. Transportation Research Part D: Transport and Environment, 41, 88-105. https://doi.org/10.1016/j.trd.2015.09.017

Baumgartner, J. P. (2001). Prices and costs in the railway sector. École Polytechnique Fédérale de Lausanne.

van den Bergh, J. C., \& Botzen, W. J. W. (2015). Monetary valuation of the social cost of CO2 emissions: a critical survey. Ecological Economics, 114, 33-46. https://doi.org/10.1016/j.ecolecon.2015.03.015

Bilow, D. N., \& Randich, G. M. (2000). Slab track for the next 100 years. In AREMA Proceedings of the 2000 Annual ConferenceAmerican Railway Engineering and Maintenance-of-Way Association.

Caetano, L. F., \& Teixeira, P. F. (2015). Optimisation model to schedule railway track renewal operations: a life-cycle cost approach. Structure and Infrastructure Engineering, 11(11), 1524-1536. https://doi.org/10.1080/15732479.2014.982133

Calle-Cordón, Á., Jiménez-Redondo, N., Morales-Gámiz, F. J., García-Villena, F. A., Garmabaki, A. H., \& Odelius, J. (2017, September). Integration of RAMS in LCC analysis for linear transport infrastructures. A case study for railways. In IOP Conference Series: Materials Science and Engineering (Vol. 236, No. 1, p. 012106). IOP Publishing. https://doi.org/10.1088/1757-899X/236/1/012106

Calvo, F., De Oña, J., López-Maldonado, G., Garach, L., \& De Oña, R. (2013). Rail track costs management for efficient railway charges. In Proceedings of the Institution of Civil Engineers-Transport (Vol. 166, No. 6, pp. 325-335). Thomas Telford Ltd.. https://doi.org/10.1680/tran.11.00001

Chevallier, J. (2012). Time-varying correlations in oil, gas and CO2 prices: an application using BEKK, CCC and DCC-MGARCH models. Applied Economics, 44(32), 4257-4274. https://doi.org/10.1080/00036846.2011.589809

Ciroth, A., Franze, J., \& Berlin, G. (2009). Life cycle costing in SimaPro. GreenDelta TC, August.

Darr, E., \& Fiebig, W. (2006). Feste Fahrbahn: Konstruktion und Bauarten für Eisenbahn und Straßenbahn. Eurailpr..

Di Mino, G., Di Liberto, C. M., \& Nigrelli, J. (2007). A FEM model of rail track-ground system to calculate the ground borne vibrations: a case of rail track with wooden sleepers and k-fastenings at Castelvetrano. In Conference on Advanced Characterisation of Pavement and Soil Engineering Materials (Vol. 2, pp. 1737-1751). LOIZOS, SCARPAS, AL-QADI.

Di Mino, G., Giunta, M., \& Di Liberto, C. M. (2009). Assessing the open trenches in screening railway ground-borne vibrations by means of artificial neural network. Advances in Acoustics and Vibration, 2009. https://doi.org/10.1155/2009/942787

Dingler, M. H., Lai, Y.-C., \& Barkan, C. P. L. (2011). Economics of expanding capacity on a single track heavy haul railway line. In: Proceedings of 11th International Heavy Haul Railway Conference, Calgary, Canada. 2011.

Du, G., \& Karoumi, R. (2014). Life cycle assessment framework for railway bridges: literature survey and critical issues. Structure and Infrastructure Engineering, 10(3), 277-294. https://doi.org/10.1080/15732479.2012.749289 
Esveld, C. (2001). Modern Railway Track, 2nd Editon. Delft university of LCC-Based Technology.

Esveld, C. (2010, May). Recent developments in high-speed track. In 1st Int. Conf. of Ballasted and Slab Tracks: on Road and Rail Infrastructure. University of Zagreb Zagreb (Croatia).

Gautier, P. E. (2015). Slab track: Review of existing systems and optimization potentials including very high speed. Construction and Building Materials, 92, 9-15. https://doi.org/10.1016/j.conbuildmat.2015.03.102

Giunta, M. (2016, November). Assessment of the sustainability of traditional and innovative rail track system. In Proceedings of International Conference on Traffic and Transport Engineering (pp. 24-25).

Giunta, M., \& Praticò, F. G. (2017, March). Design and maintenance of high-speed rail tracks: A comparison between ballasted and ballast-less solutions based on life cycle cost analysis. In Transport Infrastructure and Systems: Proceedings of the AIIT International Congress on Transport Infrastructure and Systems (Rome, Italy, 10-12 April 2017) (p. 87). CRC Press.

Infralert (2016). INFRALERT: Linear Infrastructure Efficiency Improvement by Automated Learning and Optimised Predictive Maintenance Techniques (EC H2020 Programme Grant agreement No 636496).

Jun, H. K., \& Kim, J. H. (2007, October). Life cycle cost modeling for railway vehicle. In Electrical Machines and Systems, 2007. ICEMS. International Conference on (pp. 1989-1994). IEEE.

Klockner, K., \& Toft, Y. (2018). Railway accidents and incidents: Complex socio-technical system accident modelling comes of age. Safety Science, 110, 59-66. https://doi.org/10.1016/j.ssci.2017.11.022

ISO 14040:2006 Environmental Management - Life Cycle Assessment - Principles and Framework.

ISO 15686-5:2008 Buildings and Constructed Assets. Service Life Planning. Life Cycle Costing.

Lai, Y. C., \& Barkan, C. P. (2009). Enhanced parametric railway capacity evaluation tool. Transportation Research Record, 2117(1), 33-40. https://doi.org/10.3141\%2F2117-05

Lee, C. K., Lee, J. Y., \& Kim, Y. K. (2008). Comparison of environmental loads with rail track systems using simplified life cycle assessment (LCA). WIT transactions on the Built Environment, 101, 367-372. https://doi.org/10.2495/UT080361

Leung, S. (2009, February). Carbon dioxide (CO2) emissions of concrete. Standing Committee on Concrete Technology. In SCCT Annual Concrete Seminar (Vol. 27).

Lovett, A. H., Dick, C. T., \& Barkan, C. P. (2015a). Determining freight train delay costs on railroad lines in North America. Proceedings of Rail Tokyo.

Lovett, A. H., Dick, C. T., Ruppert, C., \& Barkan, C. P. (2015b). Cost and delay of railroad timber and concrete crosstie maintenance and replacement. Transportation Research Record: Journal of the Transportation Research Board, (2476), 37-44. https://doi.org/10.3141/2476-06

Luckow, P., Stanton, E. A., Fields, S., Biewald, B., Jackson, S., \& Fisher, J. (2015). Carbon Dioxide Price Forecast. Cambridge, Massachusetts: Synapse Energy Economics. 
Mach, M. (2011). Zustandsbewertung und Nutzungsdauerprognose von Festen Fahrbahn Systemen im Netz der ÖBB. Doctor's thesis certified at Vienna University of Technology (German).

Milford, R. L., \& Allwood, J. M. (2010). Assessing the CO2 impact of current and future rail track in the UK. Transportation Research Part D: Transport and Environment, 15(2), 61-72. https://doi.org/10.1016/j.trd.2009.09.003

Oh, J. (2014). Evaluation of Track Substructure Thickness Design via Geo-Reinforcement Techniques. In Application of Nanotechnology in Pavements, Geological Disasters, and Foundation Settlement Control Technology (pp. 133-141). https://doi.org/10.1061/9780784478448.018

Pichler, D., \& Fenske, J. (2013). Ballastless track systems experiences gained in Austria and Germany. In Proc. of AREMA Annual Conference.

Popović, Z., Lazarević, L., Brajović, L., \& Gladović, P. (2014). Managing rail service life. Metalurgija, 53(4), 721-724.

Praticò, F. G., \& Giunta, M. (2016a, September). Assessing the sustainability of design and maintenance strategies for rail track by means life cycle cost analysis. In Proc., COMPRAIL 2016 15th Int. Conf. on Railway Engineering design and operation (Vol. 162, pp. 251-262). https://doi.org/10.2495/CR160231

Praticò, F. G., \& Giunta, M. (2016b). Issues and perspectives in railway management from a sustainability standpoint. DEStech Transactions on Engineering and Technology Research, (ictim). https://doi.org/10.12783/dtetr/ictim2016/5529

Praticò, F. G., \& Giunta, M. (2017). An Integrative Approach RAMS-LCC to Support Decision on De-sign and Maintenance of Rail Track. https://doi.org/10.3846/enviro.2017.144

Praticò, F. G., Vaiana, R., \& Giunta, M. (2013). Pavement sustainability: permeable wearing courses by recycling porous European mixes. Journal of Architectural Engineering, 19(3), 186-192. https://doi.org/10.1061/(ASCE)AE.1943-5568.0000127

Praticò, F. G., Vaiana, R., \& Iuele, T. (2015). Macrotexture modeling and experimental validation for pavement surface treatments. Construction and Building Materials, 95, 658-666. https://doi.org/10.1016/j.conbuildmat.2015.07.061

Praticò, F. G., Vaiana, R., Giunta, M., Iuele, T., \& Moro, A. (2013). Recycling PEMs back to TLPAs: Is that possible notwithstanding RAP variability?. In Applied Mechanics and Materials (Vol. 253, pp. 376-384). Trans Tech Publications. https://doi.org/10.4028/www.scientific.net/AMM.253-255.376

Praticò, F.G., \& Giunta, M. (2018). Proposal of a Key Performance Indicator (KPI) of railway track based on LCC and RAMS analyses. Journal of Construction Engineering and Management, 144(2). https://doi.org/10.1061/(asce)co.1943-7862.0001422

RSAC (Railroad Safety Advisory Committee) (1999). Implementation of Positive Train Control Systems, Washington, D.C.

Schafer, D., \& Barkan, C. P. (2008, September). A prediction model for broken rails and an analysis of their economic impact. In Proc., American Railway Engineering and Maintenance of Way Association (AREMA) Annual Conference. 
Schilder, R., \& Diederich, D. (2007). Installation quality of slab track-a decisive LCC-Based factor for maintenance. RTR Special-Maintenance and Renewal.

Schlake, B., Barkan, C., \& Edwards, J. (2011). Train delay and economic impact of of Ballasted and Slab Tracks: in-service failures of railroad rolling stock. Transportation Research Record: Journal of the Transportation Research Board, (2261), 124-133. https://doi.org/10.3141/2261-14

Sijm, J., Neuhoff, K., \& Chen, Y. (2006). CO2 cost pass-through and windfall profits in the power sector. Climate policy, 6(1), 49-72. https://doi.org/10.1080/14693062.2006.9685588

Silavong, C., Guiraud, L., \& Brunel, J. (2014). Estimating the marginal cost of operation and maintenance for French railway network. In ITEA Conference.

Smith, D. J. (2005). Reliability, maintainability and risk: Practical methods for engineers including RCM and safety-related systems.

Stalder, 0. (2001). The Life Cycle Costs (LCC) of Entire Rail Networks. AN International Comparison. Rail International, 32.

Stripple, H., \& Uppenberg, S. (2010). Life cycle assessment of railways for application in environmental product declarations, IVL Swedish Environmental Research Institute Ltd., Goteborg, Sweden

Thompson, L. S. (1986). High-Speed Rail. Technology Review, v. 89, pp: 32-43, 70.

Tsoukantas, S., \& Giannakos, K. (2008). Design methodology of slab track systems. Advances in Transportation Geotechnics, in Proc. of the International Conference, Nottingham, UK, 25-27 August 2008, CRC Press 2008, Pages 585-592.

Tzanakakis, K. (2013). The Railway Track and Its Long Term Behaviour. A Handbook for a Railway Track of High Quality. Volume 2 of the series Springer Tracts on Transportation and Traffic pp 279-292.

Walls, J., \& Smith, M. (1998). Life cycle cost analysis in pavement design (Report No. FHWA-SA-98-079). Washington, DC: Federal Highway Administration.

Westin, J., \& Kågeson, P. (2012). Can high speed rail offset its embedded emissions?. Transportation Research Part D: Transport and Environment, 17(1), 1-7. https://doi.org/10.1016/j.trd.2011.09.006

Xin, T., \& Gao, L. (2011). Reducing slab track vibration into bridge using elastic materials in high speed railway. Journal of Sound and Vibration, 330(10), 2237-2248. https://doi.org/10.1016/j.jsv.2010.11.023

Zoeteman, A. (2001). Life cycle cost analysis for managing rail infrastructure. European journal of transport and infrastructure research EJTIR, 1 (4).

Zoeteman, A. (2006). Asset maintenance management: state of the art in the European railways. International journal of critical infrastructures, 2(2-3), 171-186. https://doi.org/10.1504/IJCIS.2006.009436

Zwan, J. V. (2012). How to diminish the carbon footprint of asphalt roads. in Proc. of Eurasphalt and Eurobitume Congress Istanbul. 